\title{
Heart-lung transplantation for cystic fibrosis. 2: Outcome
}

B. Whitehead, P Helms, M Goodwin, I Martin, J P Scott, R L Smyth, T W Higenbottam, J Wallwork, $M$ Elliott, $M$ de Leval

\begin{abstract}
From March 1988 to March 1990, 11 children with cystic fibrosis (age 5-15 years) underwent combined heart-lung transplantation at our institutes. Maintenance immunosupression consisted of cyclosporin and azathioprine with corticosteroids and antithymocyte globulin used perioperatively and during rejection episodes. Six patients $(55 \%)$ survive from $1 \cdot 5$ 23 months all of whom have improved life quality. Actuarial survival to 1 year was $55 \%$. At six months after transplant, mean forced expiratory volume at one second was $73.5 \%$ of predicted normal, compared with $25 \%$ before transplant. There was one perioperative death, three later deaths associated with obliterative bronchiolitis at two, eight, and nine months; and one from mediastinitis at four months. Of the 15 children accepted for transplantation but not receiving grafts, 10 have died (eight within four months of being placed onto the transplant list).
\end{abstract}

Early postoperative problems included acute reversible rejection $(n=10)$, meconium ileus equivalent $(n=3)$, and pancreatitis $(n=$ 1). There was a high incidence of later pulmonary rejection with a mean of 5.7 episodes per patient in the first six months. Pulmonary infection occurred relatively infrequently, with Pseudomonas aeruginosa being the most common pathogen. Persistent diabetes mellitus requiring insulin occurred in four and systemic hypertension developed in one.

Heart-lung transplantation has been successfully used in the management of end stage respiratory disease in adults with cystic fibrosis. ${ }^{1}$ The early fears of disease recurrence and overwhelming sepsis in those transplanted have been allayed. ${ }^{2}$ This has encouraged the referral of paediatric patients with cystic fibro- sis, who currently represent the largest group being assessed for transplantation at our institutes. ${ }^{3}$ We have described our experience with the assessment of patients referred for heart-lung transplantation in the first part of this review ${ }^{4}$ and now detail outcome in those transplanted.

Patients and methods

From March 1988 to March 1990, 11 children with cystic fibrosis (age 5-15 years, mean=12) including six boys and five girls, underwent combined heart-lung transplantation. Ten were performed at the Hospital for Sick Children, London and one at Papworth Hospital, Cambridge. All patients were severely incapacitated with end stage lung disease with a mean (SD) forced expiratory volume at one second as percentage of predicted normal $\left(\mathrm{FEV}_{1} \%\right)$ of 25.0 $(10.5)$. They all had a poor quality of life with a mean (SD) Shwachman-Kulczycki score of $33 \cdot 3$ (4·3) (table 1).

Donor organs were obtained from ABO blood group and cytomegalovirus antibody compatible patients who had sustained brain death. Size matching was by predicted donor total lung capacity together with direct comparison of chest radiographs of donor and recipient. Organ evaluation and procurement were performed as previously described. ${ }^{5}$ The recipient operation ${ }^{6}$ was timed to minimise total organ ischaemia to 240 minutes.

Perioperative immunosuppression comprised cyclosporin, azathioprine, corticosteroids, and antithymocyte globulin (Atgam-Upjohn or Lymphoglobuline-Merieux) (table 2). Maintenance treatment was with cyclosporin to achieve whole blood concentrations of $600-1000 \mu \mathrm{g} / \mathrm{l}$ (modified fluorescence polarisation assay, TDx method, Abbott Laboratories) and azathioprine (ensuring total white cell count did not fall

Table 1 Details of patients with cystic fibrosis receiving heart-lung transplantation

\begin{tabular}{|c|c|c|c|c|c|c|c|}
\hline $\begin{array}{l}\text { Patient } \\
\text { No }\end{array}$ & $\begin{array}{l}\text { Age } \\
\text { (years) }\end{array}$ & Sex & $\begin{array}{l}\text { Preoperative } \\
F E V_{1} \%\end{array}$ & $\begin{array}{l}\text { Preoperative } \\
\text { Shwachman- } \\
\text { Kulczycki score }\end{array}$ & $\begin{array}{l}\text { Waiting } \\
\text { period } \\
\text { (days) }\end{array}$ & $\begin{array}{l}\text { Ischaemic } \\
\text { time } \\
(\min )\end{array}$ & $\begin{array}{l}\text { Postoperative } \\
\text { ventilation } \\
\text { (hours) }\end{array}$ \\
\hline $\begin{array}{r}1 \\
2 \\
3 \\
4 \\
5 \\
6 \\
7 \\
8 \\
9 \\
10 \\
11\end{array}$ & $\begin{array}{r}11 \cdot 5 \\
14 \cdot 0 \\
14 \cdot 3 \\
13 \cdot 2 \\
9 \cdot 7 \\
5 \cdot 8 \\
8 \cdot 1 \\
14 \cdot 2 \\
11 \cdot 9 \\
14 \cdot 3 \\
15 \cdot 3\end{array}$ & $\begin{array}{l}\mathbf{F} \\
\mathbf{F} \\
\mathbf{M} \\
\mathbf{M} \\
\mathbf{M} \\
\mathbf{F} \\
\mathbf{F} \\
\mathbf{M} \\
\mathbf{M} \\
\mathbf{F} \\
\mathbf{M}\end{array}$ & $\begin{array}{l}15 \\
21 \\
18 \\
25 \\
19 \\
15 \\
38 \\
31 \\
39 \\
43 \\
11\end{array}$ & $\begin{array}{l}\text { NA } \\
30 \\
32 \\
27 \\
35 \\
34 \\
42 \\
36 \\
36 \\
34 \\
27\end{array}$ & $\begin{array}{r}170 \\
13 \\
143 \\
7 \\
174 \\
34 \\
230 \\
73 \\
59 \\
85 \\
54\end{array}$ & $\begin{array}{r}184 \\
170 \\
170 \\
250 \\
170 \\
98 \\
210 \\
239 \\
151 \\
96 \\
204\end{array}$ & $\begin{array}{r}6 \\
64 \\
28 \\
7 \\
19 \\
14 \\
36 \\
27 \\
14 \\
8 \\
102\end{array}$ \\
\hline Mean & $12 \cdot 0$ & & $25 \cdot 0$ & $33 \cdot 3$ & $98 \cdot 8$ & 176.5 & $29 \cdot 5$ \\
\hline
\end{tabular}

NA, not applicable.
The Hospital for London B Whitehead P Helms M Goodwin I Martin $M$ Elliott
$M$ de Leva

Papworth Hospital, Papworth Everard, Cambridge

J P Scott

R L Smyth

$T$ W Higenbottam J Wallwork

Correspondence to: Dr B Whitehead, Cardiothoracic Unit, The Hospital for Sick Children, London WCIN 3JH. Accepted 8 May 1991 
Table 2 Immunosuppression for heart-lung transplantation in cystic fibrosis

\begin{tabular}{|c|c|c|c|}
\hline & Preoperative & Perioperative & Postoperative \\
\hline $\begin{array}{l}\text { Cyclosporin* } \\
\text { Azathioprine } \\
\text { Methylprednisolone (intravenous) }\end{array}$ & $\begin{array}{l}5-10 \mathrm{mg} / \mathrm{kg} \\
2 \mathrm{mg} / \mathrm{kg}\end{array}$ & $\begin{array}{l}\overline{2 \mathrm{mg} / \mathrm{kg} / \mathrm{day}} \\
10 \mathrm{mg} / \mathrm{kg} \times 2 \\
2 \mathrm{mg} / \mathrm{kg} \times 3\end{array}$ & $\begin{array}{l}5-50 \mathrm{mg} / \mathrm{kg} / \mathrm{day} \\
0.5-2 \mathrm{mg} / \mathrm{kg} / \text { dayt } \\
\text { For rejection } \\
(10 \mathrm{mg} / \mathrm{kg} \times 3)\end{array}$ \\
\hline $\begin{array}{l}\text { Antithymocyte globulin } \\
\text { Oral prednisolone }\end{array}$ & 二 & $0.5 \mathrm{ml} / \mathrm{kg} \times 3 \ddagger$ & $\begin{array}{l}\text { For rejection } \\
\text { For rejection } \\
(1 \mathrm{mg} / \mathrm{kg} / \text { day and reducing })\end{array}$ \\
\hline
\end{tabular}

*Cyclosporin administered via enteral route, together with pancreatic enzymes, three times daily.

tDose adjusted to keep white cell count $>5 \times 10^{9} / 1$

$\ddagger$ Dose adjusted according to total $T$ cell number

below $\left.5 \cdot 0 \times 10^{9} / 1\right)$. Corticosteroids were given during acute rejection episodes commencing with three daily doses of intravenous methylprednisolone $(10 \mathrm{mg} / \mathrm{kg} /$ dose $)$ followed by a reducing oral prednisolone course (starting at $1 \mathrm{mg} / \mathrm{kg} /$ day).

Initial postoperative management included early extubation and maintenance of a negative crystalloid fluid balance to prevent pulmonary oedema. Histamine $\left(\mathbf{H}_{2}\right)$ receptor antagonists (ranitidine $4 \mathrm{mg} / \mathrm{kg} /$ day) and oral antacids were administered until full enteral feeding was achieved. Regular oral acetylcysteine (Fabrol sachets, Zyma), lactulose, and pancreatic enzymes (Pancrex V powder, Paines and Byrne or Creon capsules, Duphar) were given, the latter with both food and cyclosporin. If enteral energy intake was poor (less than $0.42 \mathrm{MJ} / \mathrm{kg} /$ day) by three to four days postoperatively, intravenous feeding was instigated.

Perioperative antibiotic prophylaxis consisted of flucloxacillin $(100 \mathrm{mg} / \mathrm{kg} /$ day $)$ together with either cefotaxime $(100 \mathrm{mg} / \mathrm{kg} /$ day $)$ or gentamicin $(4 \mathrm{mg} / \mathrm{kg} /$ day with the dose adjusted to blood concentrations and renal function). In addition, appropriate antipseudomonal antibiotics (for example, ceftazidime $150 \mathrm{mg} / \mathrm{kg}$ ) day) were administered for five to seven days if this organism had been grown from the excised trachea. Co-trimoxazole (sulphamethoxazole 20 $\mathrm{mg}$ and trimethoprim $4 \mathrm{mg} / \mathrm{kg} / \mathrm{day}$ ) was given after the first week as prophylaxis against $P$ neumocystis carinii pneumonitis. ${ }^{7}$ If there was a history of recurrent herpes simplex virus infection or the patient was herpes simplex virus antibody positive, acyclovir $\left(200 \mathrm{mg} / \mathrm{m}^{2} / 8\right.$ hours) was administered over the first three postoperative months. An antifungal agent (nystatin suspension 100000 units four times a day) was continued indefinitely.

Surveillance for pulmonary rejection and/or infection was by regular clinical examination, chest radiography, ${ }^{8}$ spirometry, ${ }^{9}$ and when indicated, transbronchial biopsy. ${ }^{10} 11$ Patients were given portable microspirometers (Micro Medical) and twice daily $\mathrm{FEV}_{1}$ and forced vital capacity measurements were recorded. If there was a fall in these values of greater than 10-15\%, bronchoscopy, bronchoalveolar lavage, and transbronchial biopsies were performed. Bronchoalveolar lavage was used for bacterial and viral culture, and histopathological examination for evidence of rejection was performed on the transbronchial biopsy specimen. ${ }^{12}$ A single biospy sample was also sent to culture for opportunistic organisms. If rejection was present histologically, steroids were administered as above. Infections were treated according to culture.

Patients were discharged with their parents and siblings to a nearby family hostel after three to four weeks, where they remained for a further one to two weeks before their return home. Outpatient follow up was once a week for three months, twice a week to six months, and every three to four weeks thereafter. This included clinical assessment together with weight, blood pressure, urinalysis, and chest radiography being performed. Full blood count, concentrations of serum urea, electrolytes, creatinine, $\mathrm{C}$ reactive protein, cyclosporin, and liver function tests were routinely performed. Immunosuppression treatment was altered according to these results. Systemic hypertension was treated by calcium channel blockers (nifedipine $1-4 \mathrm{mg} / \mathrm{kg} /$ day). Persistent hyperglycaemia was managed with a twice daily regimen of insulin incorporating short and longer acting forms (Actrapid and Monotard, Novo Laboratories Ltd).

\section{Results}

The mean waiting period from acceptance onto the active waiting list to transplantation was 98.8 days (range 7-230 days). All grafts were procured distantly. Total mean (SD) organ ischaemic time was $176 \cdot 5(47 \cdot 4)$ minutes. Early graft function was good in all except patient 7. Ventilatory support was required for a mean of 29.5 hours (range 6-102 hours) and all survivors were breathing spontaneously in air by the end of the first postoperative week (table 1).

Of the 11 children who have received heartlung transplantation, six (55\%) survive from 1.5-23 months, all of whom have returned to age appropriate activities (fig 1). Although our

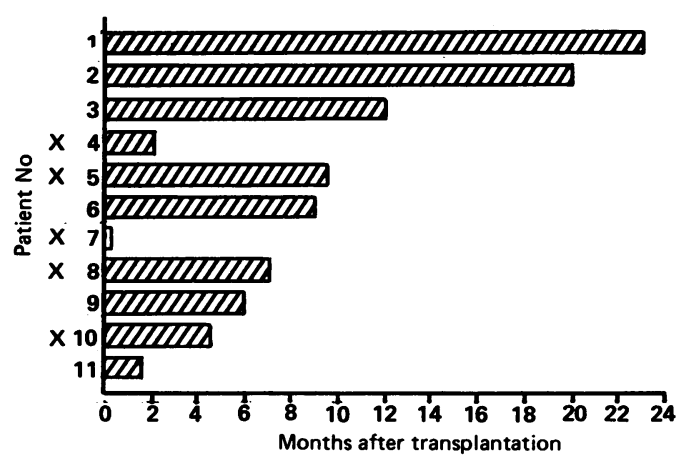

Figure 1 Survival in months of 11 patients with cystic fibrosis after heart-lung transplantation. Patients who have died are indicated by a cross. 
numbers were small and follow up limited, the actuarial survival to one year was $55 \%$ (CutlerEderer method). There were five deaths. The first (patient 4) occurred at 69 days from chronic pulmonary rejection associated with respiratory infections caused by Pseudomonas aeruginosa, Mycoplasma pneumoniae, and adenovirus. Postmortem examination of the lungs revealed obliterative bronchiolitis. The second death (patient 7) occurred at 36 hours postoperatively. This appeared to be associated with donor/recipient lung size mismatch. The smaller implanted lungs became overinflated which produced increased pulmonary vascular resistance and subsequent right heart failure. Patients 5 and 8 died at 291 and 242 days postoperatively respectively. Obliterative bronchiolitis was diagnosed in both at postmortem examination. The final death was patient 10 as a result of mediastinitis and the development of an aortic pseudoaneurysm.

Early acute pulmonary rejection, diagnosed either clinically or histologically, occurred in two patients (patients 2 and 11) during the first week, and in the surviving patients during the second week after transplantation. All were treated with intravenous boluses of methylprednisolone and showed resolution of clinical and radiological signs. Subsequent rejection episodes diagnosed histologically by transbronchial biopsy specimens were frequent. There was a mean of 5.7 episodes of rejection per patient in the seven surviving the first six months after transplant (fig 2).

Excluding the early postoperative period when antimicrobial prophylaxis was given, a total of 14 microbiologically proved and treated pulmonary infective complications, including tracheobronchitis in 12 and pneumonia in two, occurred in those seven patients surviving the first six months. These often accompanied rejection episodes (fig 2 ). This represented a mean incidence of $2 \cdot 0$ respiratory infections per patient in the first six months. The most common pathogen isolated was $P$ aeruginosa $(9 / 14)$ and Staphylococcus aureus and group A $\beta$ haemolytic streptococcus were also cultured. Adenovirus and $M$ pneumoniae were implicated on serological evidence (fourfold rise in titres) in producing a severe pneumonitis in patient 4.

Other infective events included herpes simplex labialis in three patients. Chronic medias-

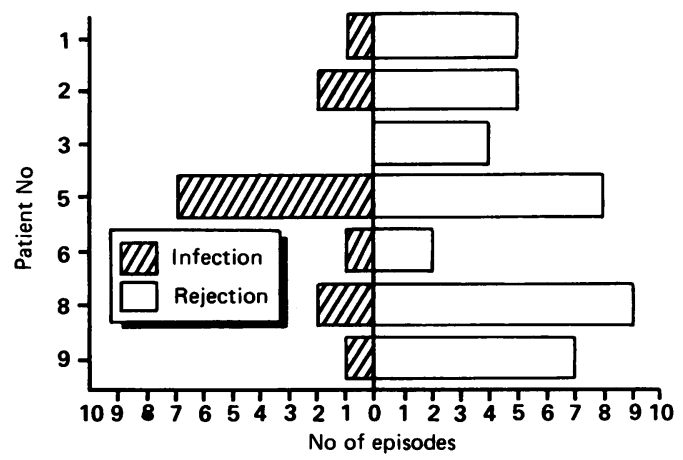

Figure 2 Number of episodes of pulmonary rejection and pulmonary infection in those cystic fibrosis patients survivin the first six months after heart-lung transplantation. tinitis due to $P$ aeruginosa associated with the development of an aortic pseudoaneurysm occurred in patient 10. Death resulted from neurological complications after resection of the aortic pseudoaneurysm. Cellulitis of the dorsum of the foot subsequent to an infected toe also developed in this patient.

Other early complications included meconium ileus equivalent, defined as subacute gastrointestinal obstruction due to inspissated faeces, which occurred in three patients (patients 2, 3, 4). This responded to medical treatment with oral acetylcysteine, aperients, and Gastrografin enemas (Schering). In the later patients in the series, prophylactic treatment with acetylcysteine was started in the perioperative period when bowel sounds were audible and continued until a regular bowel pattern was established. Pancreatitis occurred in one patient (patient 8) on day 3. This was successfully managed conservatively by gut rest and the implementation of parenteral nutrition.

Later problems included the development of diabetes mellitus subsequent to corticosteroid treatment. This occurred transiently in two patients (patients 1 and 5) and four (patients 2, $4,8,10$ ) required long term treatment with insulin.

Tracheal stenosis developed in two patients

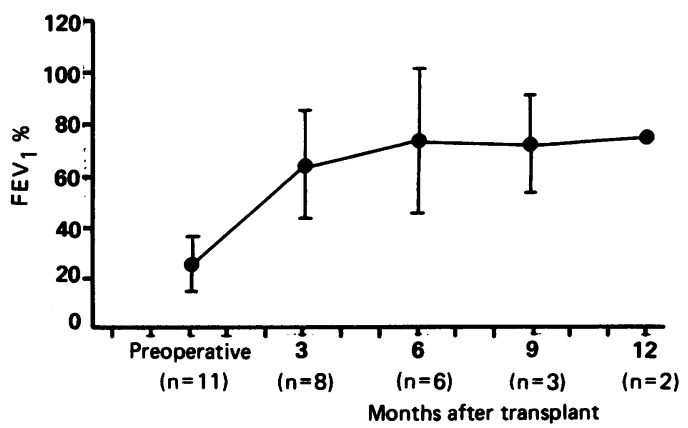

Figure 3 Mean (SD) FEV \% in patients with cystic fibrosis patients, preoperatively and to 12 months after heart-lung transplantation. The number of patients in each epoch is indicated.

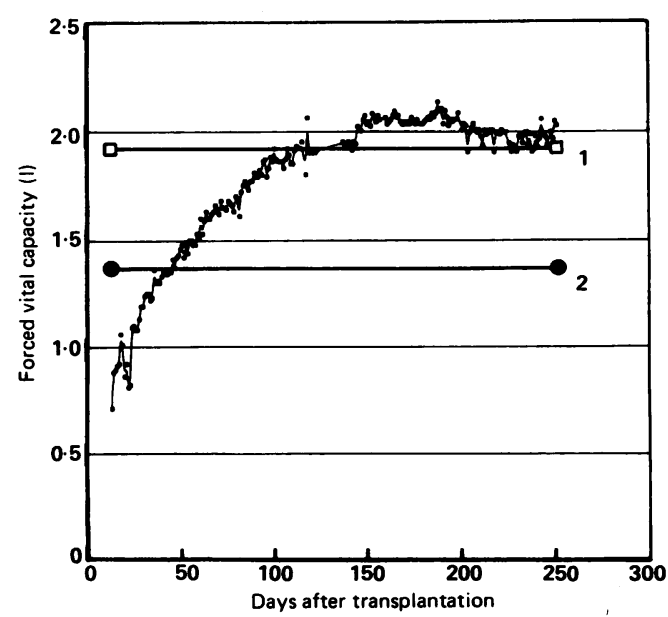

Figure 4 Forced vital capacity of patient 2 after heart-lung transplantation. Note the increase to recipient predicted values (line 1) rather than those predicted for the donor (line 2). 
(patients 5 and 8). This developed just below the tracheal anastomosis at six and three months respectively. They were successfully managed by tracheal dilatation and insertion of silastic endotracheal stents. ${ }^{13}$

Systemic hypertension requiring treatment developed in only one (patient 8) and was successfully controlled with the calcium channel blocker, nifedipine $(1 \mathrm{mg} / \mathrm{kg} /$ day $)$.

Lung function after transplant, measured by $\mathrm{FEV}_{1} \%$, showed an increase in all patients who survived beyond hospital discharge, with a mean of $73.5 \%$ at 6 months (fig 3). Lung function after transplant, measured by forced vital capacity, appeared to follow that predicted for the recipient rather than the donor (fig 4).

\section{Discussion}

The early postoperative results in our series were encouraging, with only two patients not surviving to hospital discharge. Excellent early graft function in all but one patient (patient 7) affirmed our donor selection and procurement methodology. ${ }^{14}$ Of more concern was the morbidity and mortality specifically associated with the high incidence of pulmonary rejection with or without associated respiratory infection. This appeared to lead to definite obliterative bronchiolitis in three (patients 4,5 , and 8 , which was confirmed at postmortem examination) and chronic rejection changes in two (patients 1 and 2) despite augmented immunosuppression. ${ }^{15} 16$ The increased episodes of rejection do not appear related to the pre-existing diagnosis, as adult recipients of heart-lung transplants with cystic fibrosis do not reject any more frequently than adult patients without cystic fibrosis. ${ }^{17}$

Although Bailey et al have noted less rejection in young infants receiving orthotopic cardiac transplants, ${ }^{18}$ we have noted an increased incidence in the child receiving a combined heartlung graft compared with the adult, using a similar immunosuppression and monitoring regime. ${ }^{19}$ This discrepancy remains unexplained.

Pulmonary infection often coexisted with rejection though did occur de novo. The high percentage of Pseudomonas spp isolated reflects the prevalence of this organism in patients with cystic fibrosis. The source appears to be the colonised native upper airways. Although often cultured from the respiratory tract, the majority of infections involved the tracheobronchial tree rather than the lung parenchyma. In the adult series the incidence of true pneumonia with this organism is not significantly different between recipients of heart-lung transplants with and without cystic fibrosis. ${ }^{17}$

The introduction of bronchoscopy, both flexible fibreoptic and rigid, bronchoalveolar lavage, and transbronchial biopsy in the management of our paediatric patients ${ }^{11}$ has been of great value in assessing pulmonary infection and rejection. However, these procedures are more hazardous in children and we therefore routinely use general anaesthesia and fluoroscopy to decrease the risk of complications (for example, hypoxia subsequent to a compromised airway and pneumothorax).

Pancreatitis was a clinical problem in patient 8. No infective cause was found and he responded to conservative medical management. This has been previously described occurring in adult cardiac and cardiopulmonary recipients. ${ }^{20}$ Considering the degree of pancreatic involvement in cystic fibrosis, it is surprising that more cases were not seen. This is particularly true in view of the high incidence of diabetes mellitus observed (6/11). This latter problem is a well known complication of cystic fibrosis, ${ }^{21}$ but was undoubtedly exacerbated by the high dose corticosteroids used for treatment of graft rejection.

There was a higher incidence of tracheal anastomotic stenosis (two of 11 patients $18 \%$ ), then observed in the adult series, despite identical operating techniques. This may be explained by a less well developed coronarybronchial collateral circulation in the younger patient. $^{22}$ Other paediatric series have experienced an increased incidence of this complication. ${ }^{23}$ It was of interest to note that both affected children rapidly succumbed to obliterative bronchiolitis after repeated episodes of acute allograft rejection.

Although our short term survival figures for heart-lung transplantation in cystic fibrosis compared with the current worldwide one year survival of $61 \%,{ }^{24}$ they remain lower than the Papworth Hospital adult series. ${ }^{1}$ This may be related to a greater propensity to severe graft rejection in the child, though our numbers remain too small to make confident statistical comparisons regarding this. Certainly, it seems greater control of graft rejection with improved methods of immunosuppression are required to improve the overall longer term results.

We would like to thank Mr P Goldstraw, Brompton Hospital, London, for treating our patients with tracheal stenosis and special thanks to Miss P Smith and Miss L Stanger for preparation of the manuscipt.

1 Scott J, Higenbottam T, Hutter J, et al. Heart-lung transplantation for cystic fibrosis. Lancet 1988;ii:192-4.

2 Wood A, Higenbottam T, Jackson M, Scott J, Stewart S, Wallwork J. Airway mucosal bioelectric potential difference in cystic fibrosis after lung transplantation. Am Rev Respir Dis 1989;140:1645-9.

3 Whitehead B, Helms P, Goodwin M, et al. When should children with cystic fibrosis be referred for heart-lung transplantation? Thorax 1989;44:859P.

4 Whitehead B, Helms P, Goodwin M, et al. Heart-lung transplantation for cystic fibrosis. Assessment. Arch Dis Child 1991;66:1018-21.

5 Hakim M, Higenbottam $\mathrm{T}$, Bethune $\mathrm{D}$, et al. Selection and procurement of combined heart and lung grafts for trans-

6 Jamieson SW, Stinson EB, Oyer PE, Baldwin JC, Shumway NE. Operative technique for heart-lung transplantation. f Thorac Cardiovasc Surg 1984;87:930-5.

7 Hughes WT, Kuhn S, Chaudhary S, et al. Successful chemoprophylaxis for pneumocystis carinii pneumonitis. $N$ Eng F Med 1977;297:1419-26.

8 Chiles C, Guthaner DF, Jamieson S, et al. Heart-lung transplantation: the post-operative chest radiograph. Radiology 1985;154:299-304.

9 Otulana BA, Higenbottam TW, Scott JP, et al. Pulmonary function monitoring allows diagnosis of rejection in heartlung transplant recipients. Transplant Proc 1989;21: $2583-4$.

10 Higenbottam T, Stewart S, Penketh A, Wallwork J. The diagnosis of lung rejection and opportunistic infection by transbronchial lung biopsy. Transplant Proc 1987;19: 3777-8.

11 Scott JP, Higenbottam TW, Smyth RL, et al. Experience 
with transbronchial biopsies in children after heart-lung transplantation. Pediatrics 1990;86:698-702.

12 Stewart S, Higenbottam TW, Hutter JA, et al. Histopathology of transbronchial biopsies in heart-lung transplantation. Transplant Proc 1988;20:764-6.

13 Tsang V, Goldstraw P. Endotracheal stenting for anastomotic stenosis after sleeve resection. Ann Thorac Surg 1989;48: 568-71.

14 McGoldrick JP, Scott J, Jamieson A, Smyth R, Higenbottam $T$, Wallwork J. Early graft function following heart and Tung transplantation. Transplant Int 1989;2:68-72.

15 Burke C, Glanville AR, Theodore J, Robin ED. Lung immunogenicity, rejection and obliterative bronchiolitis. Chest 1987;92:547-9.

16 Scott JP, Higenbottam TW, Clelland C, Hutter J, Wallwork $\mathrm{J}$. The natural history of obliterative bronchiolitis in patients with heart-lung transplants. Transplant Proc 1989, 21:2592-3.

17 Smyth RL, Scott JP, Higenbottam TW, et al. The use of heart-lung transplantation in the management of terminal respiratory complications of cystic fibrosis. Transplant Proc 1990;22:108-9.

18 Bailey LL, Assaad AN, Trimm RF, et al. Orthotopic transplantation during early infancy as therapy for incurable
congenital heart disease. Ann Surg 1988;208:279-86.

19 Hutter JA, Despins T, Higenbottam T, Stewart S, Wallwork J. Heart-lung transplantation: better use of resources. Am $\mathcal{f}$ Med 1988;85:4-11.

20 Aziz S, Bergdahl L, Baldwin JC, et al. Pancreatitis after cardiac and cardiopulmonary transplantation. Surgery

21 Finkelstein SM, Wielinski CL, Elliott GR, et al. Diabetes mellitus associated with cystic fibrosis. $\mathcal{F}$ Pediatr 1989;112: 373-7.

22 Baldwin JC, Jamieson SW, Oyer PE, et al. Bronchoscopy after cardiopulmonary transplantation. $\mathcal{f}$ Thorac Cardio vasc Surg 1985;89:1-7.

23 Le Bidois J, Guarnera S, Slyomans T, et al. Apsect pratique de la surveillance des greffes cardiaques et cardiopulmonaires cheq l'enfant. Arch Fr Pediatr 1998;45(suppl 1):755-9.

24 Heck CF, Shumay SJ, Kaye MP. The registry of the international society for heart transplantation: sixth official report; 1989. I Heart Transplant 1989;8:271-6.

\section{Commentary}

These two papers from the Hospital for Sick Children and Papworth Hospital give a very clear outline of their meticulous multidisciplinary team approach to the assessment of children with cystic fibrosis being considered for heartlung transplantation. The survival of $55 \%$, three months to three years after transplantation, is disappointing compared with the adult figures from Papworth, presented recently, of $78 \%$ at one year and $66 \%$ at 3 years (Cystic Fibrosis Research Trust Meeting, 1991). My experience at the Brompton Hospital was broadly similar to that of the Hospital for Sick Children, though more of my patients were not accepted on the programme and consequiently a large percentage on the active waiting list were actually transplanted.

Whitehead and colleagues have attempted to define the indices of poor short term survival based on deaths in their cystic fibrosis clinic over a 10 year period but fail to indicate how many patients with similar prognostic features survived for more than two years. Furthermore, See related papers on $p 1013$ and 1018 . plantation. The mean time to death of their 10 patients who died awaiting transplantation was only 3.7 months, suggesting that selection should be based not only on a maximum projected survival of two years without heart-lung transplantation but also a minimum of three months. This might avoid some of the inevitable anguish, recrimination, and guilt suffered by the families of those who die waiting.

From the combined figures from the Brompton Hospital and Hospital for Sick Children only a sixth of the referrals had truly benefited from heart-lung transplantation, half had died either before or after the procedure, and the remainder were still waiting. These are the harsh realities which paediatricians must now present to their patients with cystic fibrosis and families, but there are additional less well defined issues which must also be considered.

The psychosocial problems which occur in those families drawn into the transplantation programme are immense. For some the hope generated has a very positive effect but for many the whole procedure is a nightmare which ends in disaster. Heart-lung transplantation is not the miraculous cure imagined by many. It merely replaces lungs diseased by cystic fibrosis with a foreign heart and lungs at perpetual risk of rejection and an inevitable iatrogenic immunodeficiency. Even if the results improve substantially, there will never be enough hearts and lungs available for all but a minority of patients. Indeed if all patients with cystic fibrosis deemed suitable for heart-lung transplantation were referred to transplant centres, in addition to the vast number of patients with other heart and lung diseases, then the percentage achieving benefit would be tiny.

The spectre of heart-lung transplantation has already affected our practice in cystic fibrosis clinics, forestalling the well established use of pleurectomy for pneumothoraces, steroids in end stage disease, and effective terminal care. Such changes must be resisted at all costs and heart-lung transplantation should not deter continuing effort to control cystic fibrosis medically.

Can the benefit from the massive investment in heart-lung transplantation for a lucky minority really offset the suffering of the majority? This issue is far from resolution and open discussion in the journals is essential to allow us all to reach an informed opinion.

J O WARNER

Department of Child Health. Southampton General Hospital,
Tremona Road. Southampton $\mathrm{SO}^{9} 4 \mathrm{XY}$ 